\title{
Surveillance and Evaluation of the Infection Risk of Free-Living Amoebae - Acanthamoeba in Aquatic Environments
}

\author{
Bing-Mu Hsu
}

\begin{abstract}
Acanthamoeba is one kind of free-living amoebae (FLA) which ubiquitous in various aquatic environments. Several Acanthamoeba species are pathogenic and host other pathogens such as Legionella, but the presence of Acanthamoeba and its parasites as well as the related infection risk are not well known. In this study, the surveillance and evaluation of the infection risk of Acanthamoeba in different aquatic environments was investigated. Water samples were collected from a river, intake areas of drinking water treatment plants, and recreational hot spring complexes in Taiwan. A total of 140 water samples were tested for the presence of Acanthamoeba spp.. In addition, phylogenetic characteristics and water quality parameters were also assessed. The pathogenic genotypes of Acanthamoeba T4 were abundant in the hot spring water. Taken together, Acanthamoeba contamination in recreational hot springs and drinking water source warrants more attention on potential legionellosis and amoebae infections.
\end{abstract}

Index Terms-Acanthamoeba, legionella, pathogenic, hot spring, aquatic environments.

\section{INTRODUCTION}

Amoebida family belongs to Kingdom Protozoa, which can be categorized into intestinal parasitic protozoan and free-living species [1], [2]. Most amoebae are free-living and nonpathogenic to human [3]. Acanthamoeba is a genus of free-living amoebae (FLA), one of the most common protozoa in soil, fresh water human bodies, swimming pools, bottled mineral water, contact lens solutions, and even dust [4].

The shape of Acanthamoeba is usually 15 to $35 \mu \mathrm{m}$ in length and oval to triangular when moving. Acanthamoeba is able to form metabolically inactive cysts which are resistant to fluctuations in temperature and $\mathrm{pH}$ levels. Cysts are also resistant to attack by the host immune system and facilitate the recurrence of infection. Most species are free-living bacterivores, but some are opportunists that can cause infections in humans and other animals [5], [6].

Pathogenic Acanthamoeba was first isolated from dust in 1913 by Puschkarew and named Amoeba polyphagus [7], and the genus Acanthamoeba was created in 1931 by Volkonsky [1], [2]. Till now, Acanthamoeba can be classified into three subgeneric groups and 17 different genotypes [5], [6]. Some genera of Acanthamoeba cause different infections, which produces Acanthamoeba keratitis, subacute or chronic

Manuscript received April 27, 2015; revised July 31, 2015.

Bing-Mu Hsu is with the Department of Earth and Environmental Sciences, National Chung Cheng University, Chiayi, Taiwan (e-mail: bmhsu168@gmail.com). granulomatous amoebic encephalitis, and skin infections. The first cases which clearly established Acanthamoeba as causative agents of disease in humans were reported in the early 1970s. Subsequently, human infection by Acanthamoeba has been reported worldwide [8], [9]. Part of Acanthamoeba species are pathogenic for animals and humans, among which Acanthamoeba polyphaga, Acanthamoeba castellanii, and Acanthamoeba culbertsoni are the three most common species to infect human [10].

The emergence of Acanthamoeba species had certain correlation with environmental factors. In an earlier study on FLA in warm monomictic lake in South Carolina, USA, Acanthamoeba was detected at a higher rate than in other seasons [11]. Similarly, Acanthamoeba species were isolated mainly in the summer from water bodies in Oklahoma, USA [12]. Seasonal distribution may be related to the occurrence of Acanthamoeba species, but the differences have not been well evaluated.

Acanthamoeba has also been shown to support the intracellular replication and survival of human pathogens [13]. In addition, Acanthamoeba is an important reservoir of pathogenic microorganisms, protecting them from adverse conditions, disinfectants and therapeutic agents, while also enhancing their virulence in humans [14]. The aim of the study was to gain some insights into the quantity, distribution and occurrence of potentially pathogenic species of Acanthamoeba in the environmental reservoirs.

\section{MATERIALS AND METHODS}

\section{A. Sample Collection Area of Study}

The water samples were collected from an entire rivershed (Puzih River denoted as group A, sampling number: 65) in Taiwan, a raw water intake area (Kaoping River, denoted as group B, sampling number: 14) containing five drinking water treatment facilities along, and three hot spring recreation areas (denoted as group C, sampling number: 61) (Fig. 1). The sample collection took place between August, 2011 and April, 2012. At each sampling site, three water quality parameters (including $\mathrm{pH}$ level, water temperature, and turbidity) and microbial parameters (including heterotrophic bacteria and total coliforms) were assessed.

\section{B. Sample Pretreatment and DNA Extraction}

To concentrate Acanthamoeba, water sample was filtered through 45-mmdiameter GN-6 material membranes (Pall, Mexico City, Mexico) with a pore size of $0.22 \mu \mathrm{m}$ in a stainless steel filter holder. After filtration, the membranes 
were scraped, and the collected material was washed with 100 $\mathrm{mL}$ eluting fluid consisted of phosphate-buffered saline (PBS; $7.5 \mathrm{mM} \mathrm{Na}_{2} \mathrm{HPO}_{4}, 3.3 \mathrm{mM} \mathrm{NaH} \mathrm{PO}_{4}, 108 \mathrm{mM} \mathrm{NaCl}, \mathrm{pH}$ 7.2).

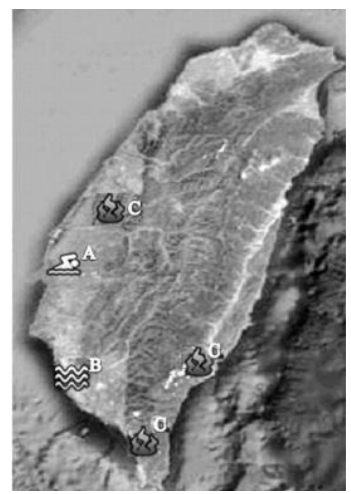

Fig. 1. Locations of sampling sites in Taiwan.

The resulting solution was then transferred into two $50 \mathrm{~mL}$ conical centrifuge tubes and centrifuged at $2600 \times \mathrm{g}$ for $30 \mathrm{~min}$. After removing the top $45 \mathrm{~mL}$, the remaining pellet was resuspended with PBS at $4{ }^{\circ} \mathrm{C}$ for further DNA extraction and
PCR. DNA extraction was obtained with the MagPurix Bacterial DNA Extraction Kit ZP02006 and automated DNA extraction by MagPurix $12 \mathrm{~s}$ Automated Nucleic Acid Purification System (Zinexts Life Science Corp., Taiwan) according to the manufacturer's specifications. The suspension was analyzed for the presence of Acanthamoeba specific genes by PCR and quantitative real-time PCR.

The primers used in reactions are summarized in Table I [15], [16]. Real-time PCR was performed using ABI StepOneTM Systems and recommended reagents (Applied Biosystems, Singapore).

\section{PCR Molecular Identification of Acanthamoeba}

For Acanthamoeba typing, theASA.S1 region of Acanthamoeba 18S rRNA gene was amplified with above primers. PCR products were electrophoresed on $2 \%$ agarose gel (Biobasic Inc., Canada) stained with a solution of ethidium bromide and visualized under UV light. The sequence analysis was done using a Bio-Dye terminator cycle sequencing kit (Applied Biosystems, USA).

\begin{tabular}{|c|l|l|l|l|}
\hline TABLE I: THE PRIMERS USED FOR IDENTIFICATION AND QUANTIFICATION OF ACANTHAMOEBA \\
\begin{tabular}{|c|l|l|l|}
\hline Polymerase chain reaction Sequences Target & genes & $\begin{array}{l}\text { Sizes } \\
(\mathbf{b p})\end{array}$ & $\begin{array}{l}\text { Annealing } \\
\text { temperature } \\
\left({ }^{\circ} \mathbf{C}\right)\end{array}$ \\
\hline Conventional PCR & $\begin{array}{l}\text { F: GGCCCAGATCGTTTACCGTGAA } \\
\text { R: TCTCACAAGCTGCTAGGGGAGTCA }\end{array}$ & 450 & 62 \\
\hline Taqman real-time PCR & $\begin{array}{l}\text { F: CCCAGATCGTTTACCGTGAA } \\
\text { R: TAAATATTAATGCCCCCAACTATCC }\end{array}$ & 180 & 52 \\
\hline
\end{tabular}
\end{tabular}

\section{Quantitative Real-Time PCR Detection of Acanthamoeba}

The TaqMan real-time PCR assay primers set were designed for Acanthamoeba gene sequence. The TaqMan realtime PCR was performed using an ABI StepOneтм Real-Time PCR Systems (Applied Biosystems, Singapore). For each assay, cycle threshold $(\mathrm{Ct})$ value was determined in order to quantify each DNA product. A negative DNA control (using double-distilled water instead of DNA template), positive DNA control (Acanthamoeba lenticulata ATCC30841), and water sample DNA were included in each run.

\section{E. Copy Number Standard Curve of the 18S rRNA Gene in Acanthamoeba}

The yT\&A clone vector kit (Yeastern Biotech Corporation, Taiwan) was used to determine the Acanthamoeba 18S rRNA gene copy number. Recombinant plasmid DNA was purified by HiYield ${ }^{\mathrm{TM}}$ plasmid mini kit (Real Biotech Corporation, Taiwan). Following purification, the concentration of plasmid DNA was determined using a NanoDrop ND1000 spectrophotometer (NanoDrop Technologies, USA). The number of construct copies in the plasmid solution was calculated based on plasmid and insert sizes. A plasmid-based standard curve was generated with tenfold serial dilutions of plasmid containing the $18 \mathrm{~S}$ rRNA gene fragment sequence of the target Concentrations were verified by quantitative real-time PCR. This plasmid-based standard curve, with a concentration of $1.3 \times 10^{8}$ gene copies per liter for the dilution with the highest copy number, was used for determining the copy number of the 18S rRNA gene in Acanthamoeba.

\section{F. Analysis of Water Quality Parameters}

Physical and microbiological parameters are based on water quality monitoring items of EPA, Taiwan, ROC. There are three water quality parameters were measured on site, including $\mathrm{pH}$ level with a portable pHmeter (D-24E, Horiba Co., Japan), water temperature with a thermometer, and turbidity with a turbidimeter (HACH Co., Loveland, CO, USA).

Additional water samples were taken for each sampling sites in $300 \mathrm{~mL}$ sterile sampling bags (NascoWhirl-Pak, USA) for microbiological water quality parameters. The samples were kept in coolers during transportation to the laboratory for subsequent analyses within $24 \mathrm{~h}$. Total coliforms weremeasured bymembrane filtration and a differential medium described in the standard method for the examination of water and wastewater (Methods 9222 B). The total coliform culture was placed in m-Endo LES agar (Difco, USA) at $36{ }^{\circ} \mathrm{C}$ for $24 \mathrm{~h}$ before counting. Heterotrophic bacteria were cultured on the M-heterotrophic plate count (HPC) agar base and measured by the spread plate method (Methods 9215C).

\section{G. Phylogenetic Analysis}

Phylogenetic analysis was conducted using MEGA version 4.0.2 (The Biodesign Institute, Tempe, AZ, USA). The phylogenetic trees were derived by the neighbor-joining method with 1,000 bootstrap simulations.

\section{H. Statistic Analysis}

Statistical analyses were performed on the presence of 
target microbes with the water quality parameters using STATISTICA version 6.0 (StatSoft, Inc., Boston, MA, USA).

\section{RESULTS AND DISCUSSION}

\section{A. Presence of Free-Living Amoebae in Different Aquatic Environments}

In this study, the presence of Acanthamoeba was determined by detecting the DNA from concentrated water samples. The detection rate of Acanthamoeba by the PCR method may be underestimated, particularly if humic acids were present in the water sample. Therefore, in the parallel experiments each sample was also cultivated to enrich Acanthamoeba before DNA extraction. The result is shown in Table II. Overall, 26.4\% (37/140) of the water samples contained Acanthamoeba spp. The highest detection rate was found in spring water $(47.5 \%)$ and following raw drinking water intake area $(43.0 \%)$. The high detection rates of Acanthamoeba spp in these two area suggested potential health concerns, since direct contact with pathogens is likely in recreational hot springs, and current water treatment procedures may not efficiently eliminate Acanthamoeba.

TABLE II: DETECTION RATES OF FLA IN DIFFERENT AQUATIC ENVIRONMENTS (NuMBERS IN PARENTHESES INDICATE TOTAL POSITIVE SAMPLES)

\begin{tabular}{|l|c|c|}
\hline Sample group & Sampling number & Acanthamoeba spp. \\
\hline Puzih River (A) & 65 & $3.1 \%(2)$ \\
\hline $\begin{array}{l}\text { Water treatment } \\
\text { plants (B) }\end{array}$ & 14 & $43.0 \%(6)$ \\
\hline Hot springs (C) & 61 & $47.5 \%(29)$ \\
\hline \multicolumn{1}{|c|}{ Total } & 140 & $26.4 \%(37)$ \\
\hline
\end{tabular}

The geographical data in the Puzih River watershed are described as below. The average annual rainfall depth is $1,855 \mathrm{~mm}$, and most of the rainfall occurs in late spring and during typhoon season between July and September. Water flow in Puzih River varies substantially over time, from 0.2 $\mathrm{m} 3 / \mathrm{s}$ during the dry seasons up to 1,100 in rainy seasons. Although the sampling time spanned across rainy and dry seasons, massive rainfalls between May and September in $2011(139.2 \pm 27.7 \mathrm{ml} / \mathrm{month}$ in the local city Chiayi) may have diluted Acanthamoeba in water bodies, thus reducing the overall detection rate. Concentrated pollutants from untreated sewage and industrial wastewater may have also decreased the sustainability of Acanthamoeba during the dry season.

\section{B. Relationships between Acanthamoeba and Water Quality Variables}

Statistical evaluations were performed on the association between detection of Acanthamoeba and various water quality parameters. The detection of Acanthamoeba spp. in water samples was significantly associated with the level of heterotrophic plate count and total coliform. The finding was consistent with the previous study of Visvesvara et al. [17]. The results suggested that recreational spring waters, with human-derived bacteria and organic compounds, may provide an ideal environment for Acanthamoeba growth.

Among samples from hot springs, pathogenic genotypes of Acanthamoeba and Naegleria were found at a higher proportion in our previous study [18]. In this study, the detection of Naegleria in hot spring water suggested potential exposure and infection risk. In contrast, the identified pathogenic FLA in water treatment plants were all of Acanthamoeba spp. A possible explanation of this discrepancy may be the higher resistance of Acanthamoeba, especially in their cyst forms, against environmental stresses such as ultraviolet radiation. The above results also showed that Acanthamoeba and Naegleria are a potential public health issue in the drinking water supply as well as in hot spring waters.

\section{Identification of Acanthamoeba}

A few genotypes of Acanthamoeba, especially the T4 group, are considered highly pathogenic to humans (Ledee et al., 2009). Thirteen Acanthamoeba-positive samples, primarily from samples with strong PCR signals, were sequenced for genotype identification. After phylogenetic analysis using various representative strains of T1-T17 genotypes as references, 11 strains of Acanthamoeba were grouped as T4 and two as T15 (Fig. 2).

Among the T4 strains, one was highly correlated with Acanthamoeba royreba, another with Acanthamoeba polyphaga. Most of the identified strains were highly correlated with Acanthamoeba castellanii, a leading cause of granulomatous amebic encephalitis (GAE). Two T15 strains were identified as A. jacobsi. Overall, most of the sequenced samples contained pathogenic Acanthamoeba strains. The potential implications on infection risks need to be further examined.

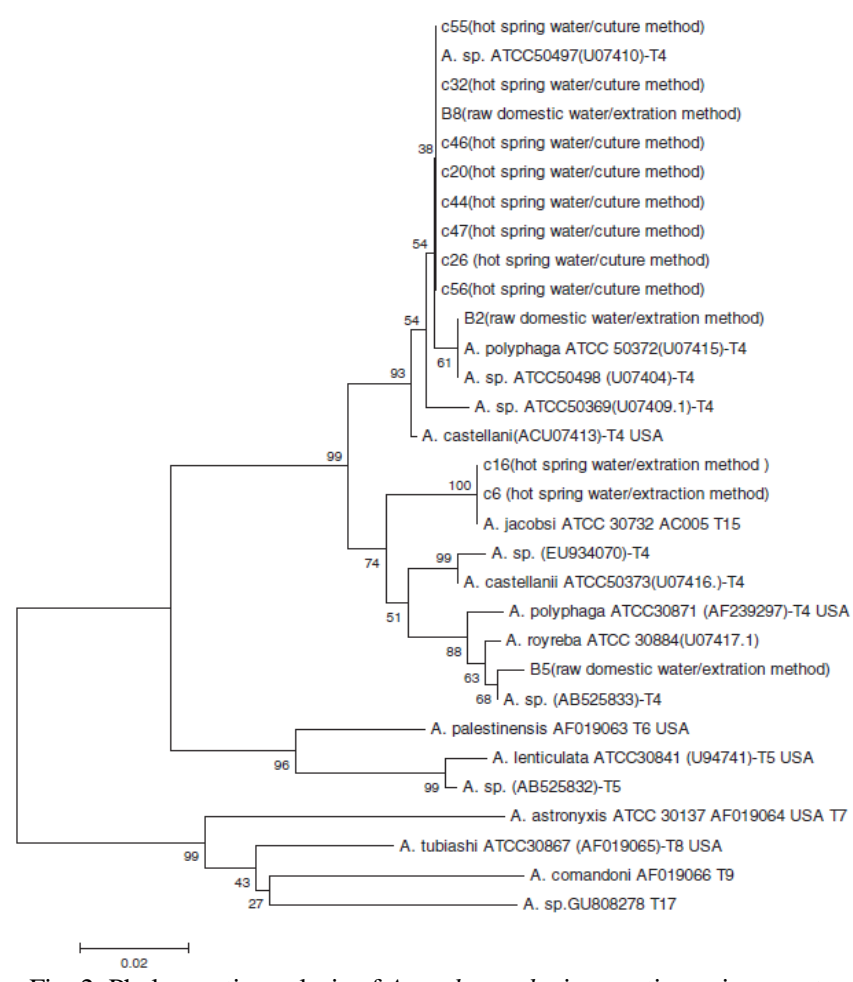

Fig. 2. Phylogenetic analysis of Acanthamoeba in aquatic environments.

\section{Quantitative Assessment of Acanthamoeba in Water Environments}

As described earlier, the detection rates of Acanthamoeba in sample groups B (raw water from water treatment plants) and $\mathrm{C}$ (hot springs) were higher than those from group $\mathrm{A}$ 
(river water). The amounts of Acanthamoeba in water samples from groups $\mathrm{B}$ and $\mathrm{C}$ were quantitatively assessed with real-time PCR, and the Acanthamoeba concentration in detected positive samples of group $B$ was ranged from $2.1 \times$ $10^{2}-7.7 \times 10^{2}$ copies/L and the average concentration was $4.8 \pm$ $2.3 \times 10^{2}$ copies/L. As for the presented Acanthamoeba concentration in spring water (group C) was ranged from 2.1 $\times 10^{2}-1.5 \times 10^{5}$ copies/L and the average concentration was 4.0 $\pm 4.3 \times 10^{4}$ copies/L.

A previous report estimated the average number of $18 \mathrm{~S}$ rRNA gene in Acanthamoeba to be about hundreds of copies per cell (Yang et al., 1994). It is possible that in water treatment plants and hot spring water, there was at least one Acanthamoeba in a liter of water. The average concentration of Acanthamoeba in group C (hot springs) was much higher than that in group B (untreated drinking water). The warm water temperature and human wastes in the recreational spring water may have been positive factors to such health threatening FLA.

\section{CONCLUSION}

In this study, Acanthamoeba was detected at high proportion in hot springs and raw drinking water and the detection of Acanthamoeba was more likely in water samples containing higher microbial concentrations. The high detection rate of pathogenic Acanthamoeba in hot springs suggested a potential risk of infection that must be further evaluated. The potential role of Acanthamoeba must be further evaluated, since Legionella harbored in Acanthamoeba are more resistant to disinfectants.

\section{REFERENCES}

[1] G. Visvesvara and F. Schuster, "Opportunistic free-living amebae, Part I," Clin. Microbiol. Newsl., vol. 30, pp. 151-158, 2008.

[2] G. Visvesvara and F. Schuster, "Opportunistic free-living amebae, Part II," Clin. Microbiol. Newsl., vol. 30, pp. 159-166, 2008.

[3] F. L. Schuster and G. S. Visvesvara, "Free-living amoebae as opportunistic and non-opportunistic pathogens of humans and animals," Int. J. Parasitol., vol. 34, pp. 1001-1027, 2004.

[4] B. Rocha-Azevedo, H. B. Tanowitz, and F. Marciano-Cabral, "Diagnosis of infections caused by pathogenic free-living amoebae," Interdiscip. Perspect Infect. Dis., vol. 2009, pp. 251406, 2009.

[5] M. R. Ettinger, S. R. Webb, S. A. Harris, S. P. McIninch, and B. L. Brown, "Distribution of free-living amoebae in James River, Virginia, USA," Parasitol. Res., vol. 89, pp. 6-15, 2003.

[6] G. C. Booton, G. S. Visvesvara, T. J. Byers, D. J. Kelly, and P. A. Fuerst, "Identification and distribution of Acanthamoeba species genotypes associated with nonkeratitis infections," J. Clin. Microbiol., vol. 43, pp.1689-1693, 2005.
[7] F. C. Page, "Re-definition of the genus Acanthamoeba with descriptions of three species," J. Protozool., vol. 14, pp. 499-521, 1967.

[8] J. Ringsted, B. Jager, D. Suk, and G. Visvesvara, "Probable Acanthamoeba meningoencephalitis in a Korean child," Am. J. Clin. Pathol., vol. 66, pp. 723-730, 1976.

[9] L. W. Hirst, W. R. Green, W. Merz, C. Kaufmann, G. S. Visvesvara, A Jensen, and M. Howard, "Management of Acanthamoeba keratitis: A case report and review of the literature," Ophthalmology, vol. 91, pp. $1105-1111,1984$.

[10] S. Kilvington and D. G. White, "Acanthamoeba: Biology, ecology and human disease," Rev. Med. Microbiol., vol. 5, pp. 12-20, 1994.

[11] D. E. Kyle and G. P. Noblet, "Seasonal distribution of thermotolerant freeliving amoebae. I. Willard's Pond," J. Eukaryot. Microbiol., vol 33, pp. 422-434, 1986.

[12] D. T. John, and M. J. Howard, "Seasonal distribution of pathogenic freeliving amebae in Oklahoma waters," Parasitol. Res., vol. 81, pp. 193-201, 1995.

[13] C. Gianinazzi, M. Schild, B. Zumkehr, F. Wuthrich, I. Nuesch, R Ryter, N. Schurch, B. Gottstein, and N. Muller, "Screening of Swiss hot spring resorts for potentially pathogenic free-living amoebae," Exp. Parasitol., vol. 126, pp. 45-53, 2010.

[14] D. E. Kyle and G. P. Noblet, "Seasonal distribution of thermotolerant freeliving amoebae. I. Willard's Pond," J. Eukaryot. Microbiol. vol. 33, pp. 422-434, 1986.

[15] S. Dhivya, H. N. Madhavan, C. M. Rao, K. S. Rao, P. V. Ramchander, K. L. Therese, and J. Malathi, "Comparison of a novel semi-nested polymerase chain reaction (PCR) with a uniplex PCR for the detection of Acanthamoeba genome in corneal scrapings," Parasitol. Res. vol.100, pp. 1303-1309, 2007.

[16] Y. Qvarnstrom, G. S. Visvesvara, R. Sriram, and A. J. Silva, "Multiplex real-time PCR assay for simultaneous detection of Acanthamoeba spp., Balamuthia mandrillaris, and Naegleria fowleri," J. Clin. Microbiol., vol. 44, pp. 3589-3595, 2006.

[17] G. S. Visvesvara, G. C. Booton, D. J. Kelley, P. Fuerst, R. Sriram, A. Finkelstein, and M. M. Garner, "In vitro culture, serologic and molecular analysis of Acanthamoeba isolated from the liver of a keel-billed toucan (Ramphastos sulfuratus)," Vet. Parasitol. vol. 143 , pp. 74-78, 2007.

[18] W.-T. Ji, B.-M. Hsu, T.-Y. Chang, T.-K. Hsu, P.-M. Kao, K.-H. Huang, S.-F. Tsai, Y.-L. Huang, and C.-W. Fan, "Surveillance and evaluation of the infection risk of free-living amoebae and Legionella in different aquatic environments," Sci. Tol. Environ., vol. 499, pp. 212-219, 2014

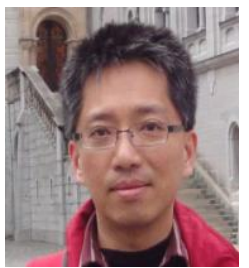

Bing-Mu Hsu received the Ph.D degree in environmental engineering from National Chiao Tung University in 2000. He joined the Faculty of Yuanpei University of Science and Technology, where he was employed as an assistant professor in 2000 and promoted to an associate professor in 2003 In 2004, he joined the Faculty of National Chung Cheng University in the Department of Earth and Environmental Sciences. He promoted to a professor in 2010.

He has published more than 65 original papers in SCI journals since 1996 (including more than 60 main-author papers). The total cited number of his papers is 590 and the average cited number is 8.64 . The H-index number is 13. Also, He has received the $2008 \mathrm{Wu}$ Ta You Memorial Award of the National Science Council and 2008 CCU Young Scholar Research Award in Taiwan. His current research interests include environmental microbiology, environmental biotechnology, environmental pathogen analysis, environmental sampling technique, and environmental risk assessment. 